\title{
Adaptação transcultural de um instrumento para avaliar a acessibilidade de alunos com paralisia cerebral ao computador
}

\author{
Gerusa Ferreira Lourenço ${ }^{a}$, Enicéia Gonçalves Mendes ${ }^{b}$
}

\author{
${ }^{a}$ Departamento de Terapia Ocupacional, Universidade Federal de São Carlos, São Carlos, SP, Brasil \\ bPrograma de Pós-graduação em Educação Especial, Universidade Federal de São Carlos, São Carlos, SP, Brasil
}

\begin{abstract}
Resumo: A literatura indica que a escolarização bem sucedida de alunos com paralisia cerebral pode requerer a implementação de recursos de tecnologia assistiva adequados, permitindo que o indivíduo melhore seu desempenho e complete tarefas cotidianas de forma mais eficiente e independente. Para tanto, esses recursos devem ser escolhidos de maneira adequada, enfatizando-se a importância de uma avaliação inicial adequada do aluno e das possibilidades de recursos presentes. $\mathrm{O}$ estudo teve como objetivo traduzir e adaptar teoricamente um instrumento norte-americano que avalia o acesso de pessoas com paralisia cerebral ao computador, de forma a contextualizá-lo para a aplicabilidade junto a alunos com paralisia cerebral na realidade brasileira. A metodologia envolveu as fases de tradução e adaptação transcultural desse instrumento, além da construção de um roteiro suplementar para uso adicional ao referido instrumento para o contexto educacional. Os procedimentos de tradução, adaptação teórica e técnica do instrumento norte-americano e a análise teórica (conteúdo e semântica) foram realizadas com a participação de profissionais especialistas na área de Educação Especial enquanto juízes. Os resultados apontaram para a pertinência da proposta do instrumento traduzido em conjunto com o roteiro construído à realidade dos profissionais envolvidos com a escolarização de crianças com paralisia cerebral como, no caso, terapeutas ocupacionais e educadores especiais.
\end{abstract}

Palavras-chave: Inclusão Educacional, Paralisia Cerebral, Tecnologia Assistiva, Avaliação, Computador.

\section{Cross-Cultural adaptation of an instrument to computer accessibility evaluation for students with cerebral palsy}

\begin{abstract}
The specific literature indicates that the successful education of children with cerebral palsy may require the implementation of appropriate assistive technology resources, allowing students to improve their performance and complete everyday tasks more efficiently and independently. To this end, these resources must be selected properly, emphasizing the importance of an appropriate initial assessment of the child and the possibilities of the resources available. The present study aimed to translate and adapt theoretically an American instrument that evaluates computer accessibility for people with cerebral palsy, in order to contextualize it for applicability to Brazilian students with cerebral palsy. The methodology involved the steps of translation and cross-cultural adaptation of this instrument, as well as the construction of a supplementary script for additional use of that instrument in the educational context. Translation procedures, theoretical and technical adaptation of the American instrument and theoretical analysis (content and semantics) were carried out with the participation of professional experts of the special education area as adjudicators. The results pointed to the relevance of the proposal of the translated instrument in conjunction with the script built to the reality of professionals involved with the education of children with cerebral palsy, such as occupational therapists and special educators.
\end{abstract}

Keywords: School Inclusion, Cerebral Palsy, Self-Help Devices, Evaluation, Computer.

Autor para correspondência: Gerusa Ferreira Lourenço, Departamento de Terapia Ocupacional, Universidade Federal de São Carlos, Rod. Washington Luís, Km 235, CEP 13565-905, São Carlos, SP, Brasil, e-mail: gerusalourenco@gmail.com

Recebido em Jan. 15, 2014; $1^{\text {a }}$ Revisão em Jun. 17, 2014; Aceito em Jul. 25, 2014. 


\section{Introdução}

A escolarização de crianças com paralisia cerebral em contextos da escola regular tem trazido a importância da proposição e uso de recursos diferenciados nas atividades curriculares e de vida diária nesse contexto (PELOSI; NUNES, 2010). Destacam-se formas alternativas de comunicação (DELIBERATO, 2011), materiais para leitura e escrita (BERSCH; PELOSI, 2007; MENDES; LOURENÇO, 2012), além de demais ferramentas que possam potencializar sua participaçáo em demais atividades (ROCHA; DELIBERATO, 2013; SILVA; MARTINEZ; SANTOS, 2012; ALPINO, 2008).

Para tanto, os alunos com paralisia cerebral devem passar por um sistema adequado de avaliaçáo de suas necessidades educacionais por todos os profissionais envolvidos, que permita estabelecer qual é o melhor local para o seu aprendizado, que determine quais são as adaptaçóes e os recursos tecnológicos que precisam ser implementados, como também as modificaçóes estruturais no ambiente necessárias, e que forneça subsídios para o planejamento das estratégicas didáticas para o acesso ao currículo escolar.

A política atual de Educação Especial na Perspectiva da Educação Inclusiva (BRASIL, 2008) tem direcionado ao uso dos recursos de tecnologia assistiva para a garantia da acessibilidade nos espaços educacionais, com fornecimento de materiais e incentivo às parcerias entre profissionais. Assim, o trabalho conjunto entre educação especial, educação regular e demais profissionais da reabilitação (como terapeutas ocupacionais, fisioterapeutas, fonoaudiólogos etc.) é valorizado e tem como uma das frentes de açáo implementar os recursos mais adequados para cada aluno (MENDES; LOURENÇO, 2012; PELOSI; NUNES, 2011).

Quanto às ações da Terapia Ocupacional na escola, estudos indicam a importância da prescriçáo adequada dos recursos de tecnologia assistiva em parceria com a escola, para que se alcancem os objetivos de proporcionar autonomia ao aluno com paralisia cerebral (ROCHA; DELIBERATO, 2013; ALVES; MATSUKURA, 2011; OKOLO; BOUCK, 2007; COPLEY; ZIVIANI, 2004).

De uma forma ampla, a Tecnologia Assistiva pode ser entendida como um campo que engloba tanto os equipamentos como os serviços que promovem ao indivíduo um sucesso maior na realizaçáo de atividades, aumentando, mantendo ou melhorando suas capacidades funcionais (COOK; HUSSEY, 2002; BRASIL, 2007). Historicamente, no país, a concepção da área e a provisão desses recursos e serviços estão presentes em diversas políticas no que tange aos direitos das pessoas com deficiência e, consequentemente, nas intervençôes em saúde e educação para essa população (MARINS; EMMEL, 2011; GALVÃO; BARROSO; GRUTT, 2013). Nessa direção, diversos grupos de pesquisa têm realizado estudos sobre a utilização desses recursos, direcionando que o desenvolvimento teórico e prático nessa área consiste em um campo promissor no país, embora ainda requeira muito investimento.

Especificamente, quanto aos recursos a serem utilizados no contexto de sala de aula, destaca-se o uso do computador e suas possíveis adaptaçóes e equipamentos como recursos que podem auxiliar os alunos com paralisia cerebral na execução de tarefas no ambiente escolar, principalmente dentro da sala de aula (BERSCH; PELOSI, 2007; BRODWIN; CARDOSO; STAR, 2004; COOK; HUSSEY, 2002; OKOLO; BOUCHY, 2007).

Nesse sentido, ao seguir a definição de tecnologia assistiva apresentada, reconhece-se o computador e seus acessórios especiais (como teclados diferenciados, mouses, acionadores e softwares) como possíveis recursos de tecnologia assistiva quando, por meio deles, atividades de comunicaçáo, escrita e leitura podem ser potencializadas. Na literatura internacional há inclusive um termo específico para essa classe de recursos: Assistive Computer Technology (ACT), que pode ser traduzida como "tecnologia computadorizada assistiva" (TCA). Esse termo é utilizado principalmente em textos sobre o uso desses recursos no ambiente escolar (MORRISON, 2007).

Sampaio e Reis (2004) afirmam que o uso de computadores por alunos com paralisia cerebral no Brasil iniciou-se em meados da década de 1980, na mesma época do movimento de introdução do interesse pelo uso do computador na educaçáo regular, e atribuem o ganho de espaço para a introdução de computadores com essa população, tanto na educaçáo especial como na regular, à facilidade de aquisição desse tipo de equipamento e à sua eficiência enquanto ferramenta para a comunicaçáo. Tais recursos vêm no sentido de proporcionar a essas crianças formas alternativas de interagir, inclusive por meio da leitura e da escrita (LIMA; MARINO; PALHARES, 2006).

Assim, uma vez reconhecido o computador como um recurso de tecnologia assistiva, a complexidade do processo de implementação com sucesso desse 
recurso no ambiente escolar deve ser entendida em um âmbito mais amplo, com variáveis além das características do próprio equipamento, como com os demais tipos de recurso (COOK; HUSSEY, 2002).

A literatura indica que o processo de implementação de um recurso de tecnologia assistiva, seja ele de baixo ou alto custo, envolve um processo bastante complexo, pois deve haver uma harmonia entre aspectos relacionados ao sujeito/ criança que irá utilizar o recurso, à atividade a ser desempenhada, ao equipamento em si e também ao ambiente em que se contextualiza esse uso (LAHM; SIZEMORE, 2002).

Estudos afirmam que compreender a interação de fatores e variáveis presentes é necessário para uma implementação bem-sucedida, minimizando frustrações e o abandono do recurso de tecnologia assistiva (PHILLIPS; ZHAO, 1993; VERZA et al.; 2006; LENKER; PAQUET, 2004; EDYBURN, 2002).

Os referenciais nacionais e internacionais partem do princípio de que um processo de implementação adequado de um recurso de tecnologia assistiva deve fundamentalmente pautar-se na avaliação das demandas do indivíduo alvo frente à tarefa que irá desempenhar naquele determinado ambiente, para uma prescrição mais efetiva do melhor tipo de recurso (FUHRER et al., 2004; EDYBURN, 2002). Para tanto, os profissionais envolvidos devem estar capacitados para esse fim, munidos de métodos e instrumentos eficazes que possam coletar as informaçóes necessárias e os direcionar pelos caminhos mais assertivos, prevenindo custos e frustraçóes.

Em busca de instrumentos de avaliação que pudessem respaldar a prática com os alunos com paralisia cerebral para a seleção dos recursos computacionais foi localizado um grupo de oito instrumentos para a consideraçáo de recurso alternativo de acesso ao computador enquanto recursos de tecnologia assistiva. Dentre esses instrumentos, um se destacou por abordar diretamente a avaliação de usuários com paralisia cerebral e poder ser aplicado tanto por profissionais da escola como da reabilitação, a saber o PCA: Physical Characteristics Assessment - Computer Access for Individuals with Cerebral Palsy (MCGREGOR et al., 1994).

O PCA foi desenvolvido devido à necessidade de sistematizar o processo de identificação de como um indivíduo com limitaçôes físicas típicas da paralisia cerebral pode acessar as ferramentas computacionais básicas (FRASER, 1994; FRASER; BRYEN; MORANO, 1995). Assim, através de um checklist ilustrado ele tem a sua aplicação destinada aos profissionais envolvidos nesse processo, tanto da área da saúde como da educação. $\mathrm{O}$ objetivo desse instrumento é guiar os avaliadores durante o processo de identificaçáo de um método de acesso $e$ entrada de informaçáo no computador para o acesso a ele, com foco nas características motoras e posturais de pessoas com paralisia cerebral. A versão original é composta por 70 questóes sequenciais divididas em oito seçôes. Um processo de eliminação é direcionado para permitir que algumas questôes sejam ultrapassadas se as respostas registradas forem positivas. Esse formato dinamiza o processo de seleção de uma estratégia de acesso ao computador, coletando informaçóes sobre:

- Partes do corpo e movimentos que podem realizar a ativaçáo do computador;

- O tipo de recurso que pode facilitar essa ativação; e

- Consideraçóes posturais básicas relacionadas com o acesso ao computador por indivíduos com paralisia cerebral.

A construção e definição do conteúdo do instrumento foram baseadas no pressuposto de que as ilustraçôes de equipamentos e os equipamentos demonstrados têm por função servir como representação de alguns tipos existentes no mercado para melhorar determinada funçáo para acesso ao computador, não sendo intenção do instrumento recomendar um produto específico. Como a evolução no desenvolvimento dessas tecnologias é ágil e novos tipos de recursos são disponibilizados diáriamente no mercado, os recursos são descritos de forma generalizada, representando uma classe/ tipo de recursos existentes.

Esse instrumento foi originalmente avaliado com relação à validade teórica, utilidade clínica e confiabilidade de respostas interjuízes e segundo a opinião dos próprios sujeitos com paralisia cerebral submetidos a ele (FRASER; BRYEN; MORANO, 1995). Participaram como juízes na validação teórica 25 profissionais; na validação empírica, 72 profissionais e 78 pessoas com paralisia cerebral de 20 diferentes locais do Canadá, Chile, Inglaterra, Israel, Espanha e Estados Unidos, sendo o instrumento traduzido para cada um dos diferentes idiomas locais. Foram avaliadas variáveis como tempo necessário para a aplicaçâo do instrumento e determinação de uma estratégia de acesso ao computador, a necessidade de mudanças nessas estratégias na fase após a introdução do recurso, 
a sensibilidade do instrumento e as opinióes dos profissionais e dos usuários sobre as dificuldades em sua aplicação. Os resultados obtidos indicaram um alto índice de significância estatística a favor do instrumento, fornecendo embasamento teórico para a sua aplicaçáo.

Assim, identificou-se o PCA: Physical Characteristics Assessment - Computer Access for Individuals with Cerebral Palsy (MCGREGOR et al., 1994) como um instrumento de interesse que poderia subsidiar uma avaliaçáo inicial de um aluno com paralisia cerebral quanto à elegibilidade de possíveis recursos computacionais para suas atividades escolares, contribuindo para uma prescrição mais adequada conforme as características motoras e posturais da criança, podendo ser uma ferramenta importante para os profissionais envolvidos com esse aluno.

A literatura atual, tanto na área de educação como da saúde, tem recomendado procedimentos de tradução e adaptação transcultural como meio de viabilizar instrumentos já validados e consagrados em diferentes culturas. Esse tipo de adaptação não envolve apenas a tradução literal e direta do conteúdo de testes e questionários, uma vez que isso é insuficiente para disponibilizar uma versão válida do instrumento de outro país ou cultura. Guillemin, Bombardier e Beaton (1993) propóem um modelo cuja metodologia revisada e refinada por Beaton et al. (2000) estabelece alguns critérios no sentido de garantir a equivalência de conteúdo, a equivalência semântica, a equivalência técnica e a equivalência conceitual do instrumento em seu processo de tradução. Para tanto, o processo envolve a adaptação dos itens individuais, das instruçôes do instrumento e das opçóes de resposta estabelecidas no original. Os autores destacam que no processo de adaptação transcultural deve-se levar sempre em conta o local para onde está sendo levado o teste (alvo), o local em que ele foi desenvolvido, principalmente com relação à língua original (fonte), e a cultura de ambos os locais. Através desses cuidados, muitas vezes, as propriedades psicométricas como validade e confiabilidade do instrumento podem ser conservadas na versão adaptada, mas ainda sem garantias, sendo necessárias análises específicas quanto ao instrumento na realidade sob a qual se pretende avaliá-lo.

De modo a garantir que o fenômeno seja realmente aferido pelo instrumento traduzido, a Psicometria estabelece alguns parâmetros mínimos na construção e/ou traduçáo desses instrumentos, conferindo a eles legitimidade e validade (PASQUALI, 1997, 2003). Dentre esses parâmetros há dois tipos de análises dos itens do teste que devem ser realizados: a teórica e a empírica. A análise teórica visa estabelecer a pertinência (análise de conteúdo) e a compreensão (análise semântica) dos itens para medir o que o instrumento se propóe. A análise empírica dos itens implica na avaliação de uma série de parâmetros que os itens devem possuir, a fim de que sejam tarefas adequadas ao fenômeno que se quer medir. Esses parâmetros são unidimensionalidade, dificuldade dos itens, discriminação, vieses, tendenciosidade de resposta, validade e precisão, avaliados estatisticamente através dos dados coletados com uma amostra de sujeitos (PASQUALI, 2003).

Nessa direção, acompanhando estudos que realizaram adaptaçóes transculturais de instrumentos para a realidade nacional (MANCINI, 2005; NOVELLI, 2003; ANDRADI et al., 2011; SANT'ANNA; BLASCOVI-ASSIS; MAGALHÁES, 2008), o objetivo da pesquisa foi traduzir e adaptar teoricamente o instrumento norte-americano PCA: Physical Characteristics Assessment - Computer Access for Individuals with Cerebral Palsy (MCGREGOR et al., 1994), de forma a contextualizá-lo para aplicabilidade junto a alunos com paralisia cerebral na realidade brasileira, a fim de que pudesse ser aplicado tanto por profissionais da saúde como da educação especial.

\section{Método}

\subsection{Participantes}

\subsubsection{Processo de tradução e adaptação}

- Tradutores: três profissionais tradutores com domínio do idioma original do instrumento - inglês.

- Juízes da tradução: membros do Grupo de Pesquisa em Formação de Recursos Humanos e Ensino em Educação Especial/ UFSCar, composto por pesquisadores com formação em Psicologia, Pedagogia e Terapia Ocupacional e uma docente do Departamento de Terapia Ocupacional da UFSCar.

\subsubsection{Análise teórica}

- Juízes para análise de conteúdo: oito professores universitários da área de Educação Especial, Reabilitação ou Psicologia que tiveram 
experiência com indivíduos com paralisia cerebral e com recursos de TA (especificamente equipamentos computacionais). A seleção dos juízes ocorreu através de consulta ao currículo do docente via Plataforma Lattes (CNPq) e também por conhecimento da pesquisadora sobre a produção bibliográfica de alguns pesquisadores sobre esse assunto.

- Juízes para análise semântica: participaram dez profissionais atuantes na Educação Especial, sendo eles dois fonoaudiólogos, dois fisioterapeutas, um psicólogo e cinco educadores.

\subsection{Procedimentos}

Para a descrição das etapas realizadas, o Tabela 1 explicita cada fase do procedimento metodológico, bem como o objetivo das etapas e seus produtos.

- Aquisição do instrumento original e autorização para traduçáo

Foi feito contato com a editora que publica o instrumento nos EUA (Don Johnston Inc.), para viabilizar a aquisição do instrumento e o contato com seus autores. Foram obtidas cópia do instrumento e autorização para a tradução e adaptação do instrumento para a realidade brasileira.

\section{- Tradução e adaptação}

Primeira versão: foi realizada uma primeira tradução minuciosa pela própria pesquisadora de todo o instrumento (manual e protocolo). A primeira traduçáo foi apresentada a uma docente do curso de graduação em Terapia Ocupacional com conhecimento da linguagem técnica da área. Com esses termos traduzidos, foi montado um glossário com definiçôes e a tradução desses termos. Chegou-se à primeira versão do instrumento.

Segunda versão: A primeira versão traduzida e a versão original foram submetidas à análise de dois tradutores separadamente. Cada um deles recebeu uma cópia do instrumento completo no idioma original (inglês), uma cópia da primeira versão traduzida e uma cópia do glossário com os termos mais específicos. Além disso foram fornecidas explicaçóes sobre os objetivos do instrumento. Após o retorno das correçóes feitas pelos tradutores, as consideraçóes foram comparadas e as poucas alteraçôes sugeridas foram contempladas, mais uma vez, reforçando a linguagem acessível do instrumento. Formulou-se, assim, a segunda versão do instrumento.

Terceira versão: A segunda versão foi então submetida a um terceiro tradutor, cuja função foi realizar a traduçáo reversa. Para tanto, ele recebeu uma cópia da terceira versáo traduzida e o glossário com os termos técnicos, que deveria traduzir do português para o inglês. A versão da tradução reversa em inglês foi comparada com o instrumento original e constatou-se que poucas foram as divergências, ligadas a alguns verbos que possuíam mais de uma definição. Ao final, montou-se a terceira versão traduzida do instrumento.

Quarta versão: todas as traduçôes e versōes foram submetidas a um comitê de especialistas do grupo de pesquisa do qual a pesquisadora fazia parte. Tal comitê foi composto por terapeutas ocupacionais,

Tabela 1. Etapas do procedimento metodológico.

\begin{tabular}{|c|c|c|c|}
\hline & DESCRIÇÃO & OBJETIVO & PRODUTO \\
\hline 1 & $\begin{array}{l}\text { Aquisição e } \\
\text { autorização }\end{array}$ & $\begin{array}{l}\text { Acessar o instrumento original e obter autorização } \\
\text { para a tradução. }\end{array}$ & $\begin{array}{l}\text { Cópia enviada pelos autores } \\
\text { e cartas de autorização. }\end{array}$ \\
\hline \multirow[t]{4}{*}{2} & Tradução & $\begin{array}{l}\text { Realização da tradução na íntegra e construção de } \\
\text { um glossário de termos. }\end{array}$ & Primeira versão \\
\hline & & $\begin{array}{l}\text { Submissão da primeira versão a dois tradutores para } \\
\text { correção. }\end{array}$ & Segunda versão \\
\hline & & Retrotradução (português para o inglês). & Terceira versão \\
\hline & & $\begin{array}{l}\text { Análise por um comitê de especialistas na área de } \\
\text { pesquisa. }\end{array}$ & Quarta versão \\
\hline 3 & Adaptação técnica & Adequação do instrumento à realidade brasileira. & Quinta versão \\
\hline 4 & $\begin{array}{l}\text { Construção do } \\
\text { Roteiro PraTA }\end{array}$ & $\begin{array}{l}\text { Confecção de um roteiro complementar para coleta } \\
\text { de informações sobre as necessidades do uso do } \\
\text { computador nas atividades escolares. }\end{array}$ & $\mathrm{PCA}+\mathrm{PraTA}=\mathrm{ICAFI}-\mathrm{PC}$ \\
\hline 5 & Adaptação teórica & $\begin{array}{l}\text { Avaliação do inventário e manual quanto à } \\
\text { pertinência e clareza dos itens. }\end{array}$ & Sexta versão \\
\hline 6 & Análise empírica & Etapa de aplicação do instrumento & Em andamento \\
\hline
\end{tabular}


psicólogos e pedagogos e a docente do curso de Terapia Ocupacional foi convidada para analisar todos os itens da tradução. Além das alterações referentes à tradução, esse grupo também sugeriu algumas modificaçôes que poderiam ser realizadas pensando na adaptação do instrumento para a realidade brasileira. Assim a quarta versão traduzida do instrumento PCA foi concluída.

\section{- Adaptação técnica do PCA}

A partir da quarta e última versão da etapa de tradução, julgou-se relevante conduzir alguns procedimentos para melhorar a adequação do instrumento para a realidade brasileira que atendessem aos objetivos do estudo, pois algumas inadequações foram constatadas. As adaptaçóes técnicas realizadas foram a exclusão de duas questôes do instrumento original, relacionadas a recursos inexistentes no mercado nacional e que não poderiam ser imediatamente substituídos por similares. Foram elas: questão na seção 2 (Ativação digital) sobre a possibilidade de acesso ao computador via Código Morse, com equipamento de ativação múltipla e rápida, e questão na seção 3 (Ativação via ponteira sustentada pela cabeça, boca ou via comando por voz), relacionada à possibilidade de ativação através do uso de uma ponteira luminosa. Uma segunda modificação foi a inserção de um campo para coletar a opinião também da família e sobre a disponibilidade de implementaçáo do recurso na escola do aluno alvo da aplicação do instrumento, uma vez que é previsto no instrumento original que, após a aquisição das estratégias de acesso ao computador, deve-se levar em consideração também a opinião do usuário. Com essas modificaçóes foi formulada a quinta versão da tradução e adaptação do PCA para a realidade nacional.

- Construção do Roteiro para o Planejamento da Prescrição de Recursos de Alta Tecnologia no Ambiente Escolar (PraTA)

O PCA tem como característica a aplicabilidade em diversos contextos, para viabilizar o uso do computador aos indivíduos com paralisia cerebral em clínica, em casa, no trabalho e na escola. Julgou-se procedente elaborar um roteiro complementar ao uso do instrumento, na tentativa de colher informaçóes que pudessem subsidiar a busca de recursos computacionais como ferramenta alternativa para o processo de ensino-aprendizado desse aluno. Dessa forma, juntamente com a quinta versão do instrumento foi desenvolvido um roteiro denominado Roteiro para o Planejamento da Prescrição de Recursos de Alta Tecnologia no
Ambiente Escolar - PraTA, seguido por manual de instruçôes e constituído por três partes:

- Identificaçáo do aluno;

- Desempenho nas atividades acadêmicas em sala de aula;

- Interesse na implementação do computador.

O objetivo desse roteiro é contextualizar o uso do PCA para o ambiente de sala de aula, coletando informaçóes sobre o aluno, o seu desempenho em sala de aula e o interesse da comunidade escolar e do aluno na implementaçáo do computador nesse ambiente. Assim, a proposta desse roteiro é subsidiar a aplicação do PCA de modo a suplementar a avaliaçáo quando se tem como alvo um aluno com paralisia cerebral no contexto educacional. A sua construção foi baseada na sistematização de questôes que coletassem dados importantes apontados tanto pela literatura como pelas experiências práticas de implementação de recursos de tecnologia assistiva e computador realizadas pelo grupo de pesquisa do qual a pesquisadora fazia parte. A proposta é que esses instrumentos sejam aplicados por profissionais como professores de Educação Especial, terapeutas ocupacionais, fisioterapeutas, fonoaudiólogos, em diálogo constante com o professor do aluno a ser avaliado.

Unindo-se o roteiro com a tradução do instrumento, chega-se 100 itens de avaliação, divididos em cinco partes, resumidas no Tabela 2.

\section{- Adaptação teórica dos instrumentos}

$\mathrm{Na}$ tentativa de conferir validade à proposta de roteiro (PraTA) e à adaptação transcultural do instrumento PCA, definiu-se os passos com a realização da análise de conteúdo e semântica dos itens.

A análise de conteúdo visa aferir se o instrumento avaliado mede o que se propóe a medir. Ou seja, se a versão traduzida e adaptada do PCA, em conjunto com o Roteiro PraTA, fornecem meios sistemáticos para possibilitar possíveis estratégias de acessibilidade ao computador a alunos com paralisia cerebral. Foi realizada tendo com juízes especialistas na área de Educação Especial que tiveram experiência com indivíduos com paralisia cerebral e com recursos de TA (especificamente equipamentos computacionais). De modo a viabilizar um método condizente com a proposta do estudo ao uso do Roteiro em conjunto com o PCA, para a análise pelos juízes foi elaborado um inventário denominado Inventário de Características Físicas para Avaliar a Acessibilidade de Alunos com Paralisia Cerebral ao Computador- ICAFI-PC. 


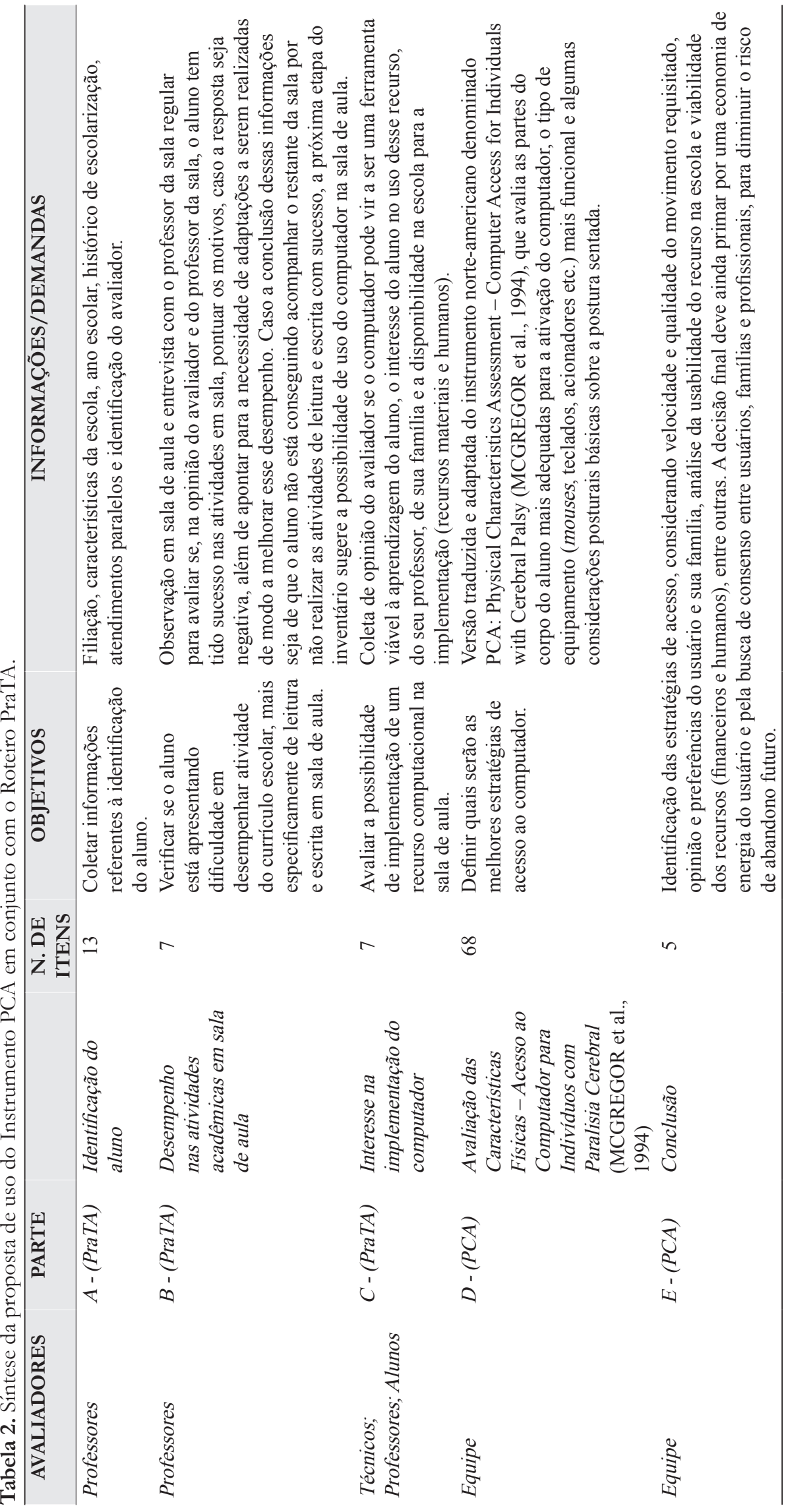


O ICAFI-PC apresentado aos juízes totalizou 100 itens, indicando o conteúdo das informaçóes a que eles se referiam. Os juízes avaliaram os itens enquanto Pertinentes $(\mathrm{P})$ ou Não pertinentes aos objetivos dos instrumentos (NP). Além disso, os juízes podiam se omitir da avaliação $(\mathrm{O})$, sem influenciar o nível de concordância sobre a pertinência do item no processo de análise de conteúdo. O cálculo utilizado para o índice de concordância entre as respostas dos juízes se dá pela divisão do total de respostas como pertinentes $(\mathrm{P})$ pelo total de respostas emitidas pelos juízes $(\mathrm{P}+\mathrm{NP})$, multiplicado por 100 (FAGUNDES, 1985). Os juízes foram instruídos a fornecerem justificativas quando assinalassem as categorias Não pertinente ou Omitido, de modo a contribuir com uma futura reformulação desse item e aprimoramento do instrumento.

O material foi enviado aos juízes via correio eletrônico e também impresso, via correspondência, conforme a preferência do juiz. O prazo de devoluçáo média foi de cerca de um mês, tendo sido estendido quando solicitado.

Todas as respostas recebidas foram transcritas em protocolos e planilhas. Em um primeiro protocolo foram transcritas todas as alternativas assinaladas por cada um dos juízes e, depois, esses dados foram transcritos e analisados em planilhas de análise de dados no software Microsoft Excel (MENEGASSO, 2005).

As falas dos juízes, desde as justificativas no julgamento do item como Náo pertinente, as Omissôes e também as sugestôes, descritas conforme a parte do ICAFI-PC a qual foram dadas, foram analisadas a partir da metodologia de análise de conteúdo descrita por Bardin (1997), com a derivação de categorias de análise. Em seguida, foram analisadas quantitativamente e subsidiaram modificaçôes nos instrumentos.

A categoria Reformulação do objetivo dos instrumentos (RO) dizia respeito às críticas e sugestôes realizadas por alguns juízes tanto com relação a itens específicos como também sobre o formato dos instrumentos, enquanto ferramenta direcionada a profissionais da área da saúde e da educaçấo, para direcionar estratégias de acesso ao computador a alunos com paralisia cerebral.

A categoria Outros tipos de recursos e adaptaçóes (OR) foi formulada a partir das sugestóes de outros tipos de recursos e adaptaçôes não abordados nessa versão do PCA. Ainda nesse sentido, a categoria Partes do corpo para ativação (PA) conglomerava as sugestóes de outras partes do corpo possíveis de serem utilizadas para a ativação do computador e não mencionadas.
Das características do aluno, tanto com relação às suas necessidades específicas como às suas capacidades, derivou-se a categoria Caracterização do aluno (CA).

A categoria Caracterização da dinâmica escolar (CE) dizia respeito às sugestóes de itens que coletassem informaçôes sobre a dinâmica escolar e à disponibilidade de implementação do recurso.

A categoria Formato dos instrumentos (FI) englobava as sugestôes de mudanças no formato dos instrumentos ou de um item específico.

$\mathrm{Na}$ categoria Reformulação semântica (RS) estavam inseridas sugestôes como alteraçôes de termos utilizados e necessidade de maior descriçáo dos movimentos mencionados, propostas para a reformulação de itens visando a uma melhor compreensão.

A adaptação teórica também envolveu os procedimentos de análise semântica dos instrumentos, realizada em duas etapas: a primeira fase com a análise das contribuiçóes do primeiro grupo de juízes, a partir das categorias Formato dos instrumentos e Reformulação semântica; em seguida, com o segundo grupo de juízes composto pela população que deverá utilizar o instrumento, no caso, profissionais da área da saúde e da educação que atuam com alunos com PC e recursos de alta TA (dispositivos computacionais).

$\mathrm{Na}$ primeira fase da análise semântica, após classificadas as falas, as categorias que diziam respeito à semântica foram destacadas e subcategorias foram criadas: Semântica sintática correspondia às críticas e sugestôes referentes à ordem das palavras nas sentenças dos itens e as sugestôes de substituição ou inserção de palavras nessas frases; e Semântica operacional relacionava-se à falta de objetividade do item, imprecisão dos termos ou a solicitação de uma descrição mais detalhada.

Com a análise semântica inicial concluída, uma sexta versão do instrumento foi construída e enviada especificamente para a segunda fase da análise semântica, em que 10 profissionais puderam avaliar o conjunto dos instrumentos quanto à clareza dos itens. Todas as falas foram novamente alocadas nessas subcategorias, em protocolos de análise semântica, e os dados foram analisados quantitativamente com o uso do software Microsoft Excel.

\section{- Análise empírica do instrumento}

A análise empírica é uma etapa imprescindível para a validaçáo de instrumentos que atribuam valores aos aspectos analisados, principalmente quanto há a comparação com um índice normativo. 
Para tanto, deve ser realizada com a aplicação da versão traduzida e adaptada em uma população estatisticamente significante, que confira validade ao instrumento. O PCA é caracterizado por um guia de avaliação e sua análise empírica encontra-se em andamento, com a aplicação do instrumento por dois grupos de pesquisa que trabalham com recursos computacionais adaptados e alunos com paralisia cerebral, visando coletar informaçóes quanto ao tempo de aplicação e ao processo de escolha do recurso computacional (MENDES; LOURENÇO, 2011; SAMESHIMA et al., 2013).

\section{Resultados}

Os resultados apresentados dizem respeito à síntese das análises dos juízes para o processo de análise teórica. Primeiramente serão apresentados os dados quanto à análise de conteúdo e em seguida quanto à análise semântica.

Quanto à pertinência dos itens, conclui-se que dos 100 itens que foram analisados pelos juízes, 96 (96\%) apresentaram 100\% de concordância sobre a sua pertinência aos objetivos do inventário, seguido por três (3\%) que apresentaram $88 \%$ e apenas um item $(1 \%)$ teve $75 \%$ de concordância.

As falas dos juízes com relação aos itens considerados não pertinentes e às omissões e todas as demais colocações (sugestôes) foram transcritas em um protocolo, sendo divididas conforme a parte do inventário, organizando-se assim o processo de derivação de categorias. Optou-se por descrever as críticas e as sugestóes de forma conjunta por ambas trazerem contribuiçóes ao aperfeiçoamento da versão traduzida e adaptada do PCA e ao Roteiro PraTA.

Quantitativamente, todas as categorias formadas tiveram seus itens contabilizados segundo os instrumentos, conforme descrito na Tabela 3.
A categoria RS se destacou pela maior parte das contribuiçôes, totalizando 35\% das 139 sugestóes e críticas realizadas pelos juízes ao inventário no processo de análise de conteúdo.

Ao somar a proporçáo de RS e FI, alcança-se $48 \%$ de todos os comentários, demonstrando-se que quase metade de todas as ressalvas realizadas pelos juízes dizia respeito à estrutura dos instrumentos, tanto quanto à semântica como quanto à distribuiçáo de seus tópicos, e não diretamente ao seu conteúdo, que foi o alvo da análise. Esse alto índice indica que o processo de análise semântica dos instrumentos pode ser iniciado juntamente com a análise de conteúdo.

Especificamente com relação ao conteúdo dos instrumentos, destaca-se a categoria OR, com sugestóes de equipamentos como diferentes tipos de acionadores, recursos para posicionamento e adaptações, seguida pela categoria CA, com a sugestão de inserção de novos itens que permitam coletar mais informações sobre as características e as capacidades do aluno, respectivamente com $16 \%$ e $10 \%$ do total das falas dos juízes.

É importante ressaltar que tanto a categoria OR como a categoria PA foram formadas basicamente por sugestóes de novas possibilidades de acesso ao computador, contribuindo para o processo de adaptação do instrumento PCA à realidade nacional.

Sobre a dinâmica escolar, a categoria correspondente totalizou $8 \%$ das sugestóes, no sentido de enfocar mais os instrumentos em relação às possibilidades de implementação do recurso no ambiente escolar.

Por fim, a categoria com o menor número de comentários foi a correspondente às modificaçôes necessárias para atender aos objetivos dos instrumentos (RO), contando com apenas $6 \%$

Tabela 3. Frequência das falas dos juízes conforme categoria de análise e instrumento.

\begin{tabular}{|c|c|c|c|c|c|c|c|c|c|}
\hline & \multicolumn{9}{|c|}{ Categoria de análise } \\
\hline & $\begin{array}{c}\text { ICAFI- } \\
\text { PC }\end{array}$ & RO & RS & OR & PA & $\mathrm{CA}$ & $\mathrm{CE}$ & FI & Total \\
\hline Roteiro & A & 4 & 6 & & & 7 & 2 & 1 & 20 \\
\hline \multirow[t]{2}{*}{ PraTA } & B & & 5 & & & 2 & 1 & 3 & 11 \\
\hline & $\mathrm{C}$ & & 1 & 1 & & & 5 & & 7 \\
\hline \multirow[t]{2}{*}{ PCA } & $\mathrm{D}$ & 2 & 33 & 16 & 15 & 5 & 2 & 11 & 84 \\
\hline & $\mathrm{E}$ & 3 & 4 & 5 & 1 & & 1 & 3 & 17 \\
\hline \multirow{2}{*}{\multicolumn{2}{|c|}{ Total }} & 9 & 49 & 22 & 16 & 14 & 11 & 18 & 139 \\
\hline & & $6 \%$ & $35 \%$ & $16 \%$ & $12 \%$ & $10 \%$ & $8 \%$ & $13 \%$ & $100 \%$ \\
\hline
\end{tabular}

RO - Reformulação ao objetivo dos instrumentos; RS - Reformulação semântica; OR - Outros tipos de recursos e adaptações; PA - Partes do corpo para ativação; CA - Caracterização do aluno; CE - Caracterização da dinâmica escolar; FI - Formato dos instrumentos. 
de todas as sugestóes e críticas. Isso indica que, de um modo geral, todos os itens formulados, inclusive a utilizaçáo do PCA em conjunto com o Roteiro PraTA, estão condizentes com a proposta de estabelecer estratégias de acesso ao computador para alunos com PC.

Pode-se verificar que a versão traduzida e adaptada do instrumento PCA recebeu críticas e sugestóes em todas as categorias de análise, com destaque para a Reformulação semântica, que concentrou $68 \%$ dos dados dessa categoria.

Embora o Roteiro PraTA também tenha recebido críticas e sugestôes relacionadas à semântica, as categorias de destaque foram Características do aluno e Características da dinâmica escolar, com, respectivamente, 10 e 9 falas do total de 14 e 11 . Esses dados indicam que foram feitas sugestôes que reforçam a pertinência do detalhamento sobre as demandas do aluno e da escola para o planejamento de implementação do recurso em sala de aula.

De uma maneira geral, descontando-se a necessidade de reformulação semântica e de modificaçóes no formato do instrumento correspondentes à melhor compreensão de seus itens, os juízes realizaram sugestôes e críticas relacionadas a outros tipos de recursos e equipamentos que podem vir a ser testados para o acesso ao computador, como também a possibilidade de ativação por outras partes do corpo além da proposta pelo instrumento. Isso traz indicaçóes de que a área de produção e disponibilização de equipamentos está se modificando, com tendência de crescimento na diversidade de recursos à disposição dos profissionais e usuários.

A primeira fase da análise semântica foi realizada a partir das categorias Reformulação semântica e Formato dos instrumentos, que diziam respeito ao julgamento dos juízes de análise de conteúdo relacionado à compreensão dos itens dos instrumentos PCA e Roteiro PraTA, seguido pela análise semântica por juízes específicos dessa etapa. Todas as críticas e sugestôes categorizadas nesse sentido foram contabilizadas e as da categoria RS foram reclassificadas em duas categorias (Semântica sintática e Semântica operacional) (MENEGASSO, 2005). A análise dessas subcategorias com relação aos instrumentos indicou que $67 \%$ das respostas (34) estão contidas na subcategoria Semântica operacional, contra 33\% (15) na Semântica sintática.

Pode-se verificar que a maior parte das contribuições dentro da categoria Reformulação semântica disse respeito à necessidade de reformulaçáa dos itens, de modo a aprimorar a sua objetividade e precisão, como a sugestão de descriçóes mais detalhadas sobre os conceitos abordados.

Relacionadas à sintaxe da frase propriamente dita, foram feitas sugestôes de substituição de termos utilizados e de reformulaçáo na ordem das sentenças dos itens.

A partir desses dados, pode-se afirmar que a maior parte das falas dos juízes, especificamente sobre reformulação semântica dos instrumentos, está centrada no instrumento PCA, o qual também continha o maior número de itens para análise. Dentre essas falas, verifica-se a necessidade em realizar modificaçóes que promovam um melhor entendimento conceitual, principalmente relacionado ao posicionamento do aluno com PC (Seção 8 - Consideraçóes Posturais) e aos movimentos corporais requisitados para o acesso ao computador (Seção 1 - Partes do Corpo para Ativação).

Com relação à categoria Formato dos instrumentos, as críticas e sugestôes estiveram centradas nas opçôes de divisão de itens, em inserçáo de espaços para registros de outras informaçôes e expansão de partes dos instrumentos. Novamente, o instrumento PCA recebeu o maior número de críticas e sugestóes relacionadas ao seu formato, totalizando $78 \%$ da categoria.

Tendo como parâmetro o peso de cada uma dessas categorias no montante das sugestóes de reformulação dos instrumentos, alguns indicativos de mudança puderam ser delineados.

O referencial metodológico utilizado nesse trabalho indicou que para a permanência do item deve ser obtido um índice de concordância maior do que $80 \%$ entre os juízes, mas que acima de $70 \%$ esse item é aceitável (PASQUALI, 2003). Como no processo de análise da concordância entre os juízes sobre a pertinência do item todos os itens apresentaram índice maior que $75 \%$, não foi necessária a exclusão de nenhum deles. Assim, as modificaçôes tiveram de ser direcionadas no sentido da inserção de novas informaçóes ou itens nos instrumentos, conforme as sugestóes dos juízes. Ao analisar as categorias e visando ao aprimoramento do conteúdo, foram consideradas as sugestôes que mais se repetiam dentro de cada uma das categorias.

Para a inserçáo de um novo item, de modo a manter o valor da análise de conteúdo já realizada, a sugestão de alteração ou ampliação no conteúdo deveria ter sido realizada por pelos menos cinco dos juízes, mas nenhuma das recomendaçóes atingiu 
esse índice. Entretanto, as sugestôes que mais se repetiram, mesmo não tendo atingido esse número de juízes, foram inseridas no manual de instruçóes dos instrumentos, de modo a direcionar o avaliador a levar em conta esses novos aspectos.

$\mathrm{Na}$ Tabela 4 estáo apresentados todos os novos aspectos e propostas de modificaçôes realizadas nos manuais de instruçôes do Roteiro PraTA e do PCA.

Especificamente com relação aos outros tipos de recurso sugeridos pelos juízes, foram mantidos apenas os recursos disponíveis para comercialização no mercado nacional. Por esse motivo, itens sobre acionadores por sopro, por sucção e ponteiras luminosas não foram inseridos.

Uma forte demanda por mudanças apresentada pelos juízes dizia respeito à forma escrita de ambos os instrumentos, reforçando a necessidade da segunda etapa de análise semântica. Todas as sugestóes dadas pelos juízes da análise de conteúdo foram levadas em conta no que dizia respeito à elegância e compreensão dos itens, no aprimoramento dos instrumentos. Assim, com a quinta versão do instrumento construída, em sua

Tabela 4. Modificações sugeridas pelos avaliadores inseridas na versão quinta do manual do PCA e no manual do Roteiro PraTA.

\begin{tabular}{|c|c|}
\hline & PARTE A - Identificação do aluno \\
\hline \multirow[t]{11}{*}{ Roteiro PraTA } & Buscar: \\
\hline & $\begin{array}{l}\text { - Informações referentes ao diagnóstico médico do aluno ou caracterização de seu prejuízo } \\
\text { motor; }\end{array}$ \\
\hline & - Maior detalhamento do vínculo do avaliador com a escola. \\
\hline & PARTE B - Desempenho do aluno nas atividades acadêmicas em sala de aula \\
\hline & Buscar: \\
\hline & $\begin{array}{l}\text { - Informações referentes ao desempenho do aluno em atividades específicas (escrita, leitura, } \\
\text { matemática etc.); }\end{array}$ \\
\hline & $\begin{array}{l}\text { - Detalhamento dos tipos de adaptações ou recursos que já estão sendo utilizados pelo aluno } \\
\text { no ambiente da sala de aula. }\end{array}$ \\
\hline & PARTE C - Interesse na implementação do computador \\
\hline & Buscar: \\
\hline & $\begin{array}{l}\text { - Informações sobre a capacitação e a disponibilidade do professor para o uso do } \\
\text { computador com esse aluno; }\end{array}$ \\
\hline & - Informações sobre como será a aquisição do recurso. \\
\hline \multirow[t]{16}{*}{ PCA } & $\begin{array}{l}\text { Parte D - Avaliação das características físicas de indivíduos com paralisia cerebral para o } \\
\text { acesso ao computador }\end{array}$ \\
\hline & Buscar: \\
\hline & Seção 1 \\
\hline & $\begin{array}{l}\text { - Avaliar a capacidade de sopro, sugar e piscar para possibilidades futuras de acesso via esse } \\
\text { tipo de acionador no mercado nacional; }\end{array}$ \\
\hline & Seção 2 \\
\hline & $\begin{array}{l}\text { - Verificar a possibilidade de estabilizar uma das mãos com velcro durante o acionamento do } \\
\text { computador; }\end{array}$ \\
\hline & Seção 3 \\
\hline & $\begin{array}{l}\text { - Verificar se o usuário necessita de um sistema de suporte para estabilizar a cabeça durante } \\
\text { as atividades no computador; }\end{array}$ \\
\hline & Seções $4,5,6$ e 7 \\
\hline & - Especificar o tipo de acionador que está sendo utilizado na avaliação; \\
\hline & Seção 8 \\
\hline & $\begin{array}{l}\text { - Especificar os tipos de recursos para posicionamento que estão sendo utilizados na } \\
\text { avaliação (textura, tamanho etc.). }\end{array}$ \\
\hline & PARTE E - Conclusões \\
\hline & Buscar: \\
\hline & - Reflexão sobre a melhor estratégia de acesso - maior eficiência para o usuário; \\
\hline & $\begin{array}{l}\text { - Verificar a disponibilidade de implementação do recurso e propor estratégias alternativas } \\
\text { quando necessário. }\end{array}$ \\
\hline
\end{tabular}


última avaliação semântica, os juízes específicos para essa etapa elencaram a necessidade de modificação em alguns termos ou inserção de sinônimos (como trackball, joystisck) e também no formato de alguns itens específicos do Roteiro PraTA. É importante destacar que foram mínimas as sugestôes de modificaçóes por esses juízes, o que indica a adequação do processo de adaptação do PCA a partir das contribuiçôes do primeiro grupo de juízes na análise de conteúdo.

Quanto à análise empírica, em contínua realização, os grupos de pesquisa envolvidos com essa etapa têm certificando o uso do instrumento para a sistematização do processo de avaliação e escolha do equipamento mais adequado (SAMESHIMA et al., 2013).

\section{Discussão}

Com a proposta de contribuir para o desenvolvimento teórico no país da implementação de recursos de tecnologia assistiva no ambiente educacional junto a alunos com paralisia cerebral, a proposta do uso do PCA em associação ao Roteiro PraTA fornece subsídios para o processo inicial de avaliação e prescrição do recurso, uma vez que permite coletar informaçôes diretas sobre três importantes aspectos: quais são os problemas funcionais do indivíduo frente a uma tarefa, sobre os quais se busca um impacto com o uso de determinado recurso; quais são as características principais do recurso que o caracterizam como o mais provável para esses impactos traçados; e quais são as características dos indivíduos que os tornam candidatos a serem usuários em potencial de recursos de tecnologia assistiva, como apresentado por Fuhrer et al. (2003).

Segundo Lenker e Paquet (2004), o papel da prescrição adequada de um recurso é diretamente ligado à fase inicial de contato do usuário com o recurso, influenciando a motivação e o reconhecimento pelo usuário das vantagens ou desvantagens do seu uso, o que afetará de forma determinante o caráter de usabilidade e todo o restante do processo de implementação.

Com relaçáo a esse processo de adoção do recurso dentro do ambiente educacional, Duhaney e Duhaney (2000) ressaltam a importância de um processo de planejamento cuidadoso e diretrizes bem definidas para a sua implementação, tendo em vista o número significativo de recursos atualmente disponíveis. Dalton (2002) aponta para a participação do aluno, dos familiares e do corpo escolar no processo de escolha e planejamento do uso do recurso, contextualizando o uso do Roteiro PraTA proposto.

Apesar do intuito do estudo de oferecer aos profissionais envolvidos na escolarização de alunos com paralisia cerebral subsídios para conseguir formular uma estratégia de acesso ao computador para esses alunos, no Brasil parece ainda haver um caminho nebuloso na definição de quem seriam os profissionais a exercer esse tipo de papel no âmbito escolar. Devido à complexidade do processo de avaliação e prescrição de um recurso de tecnologia assistiva, reforça-se a importância do trabalho em equipes, pois os profissionais da escola (professores, professores da educaçáo especial, educadores físicos) e os profissionais externos, como fisioterapeutas, terapeutas ocupacionais, psicólogos e fonoaudiólogos, necessitam do trabalho em conjunto, compartilhando saberes para conseguirem avaliar todas as variáveis envolvidas.

Nesse sentido, a opção pelo instrumento PCA e a proposta do Roteiro PraTA também têm como intuito favorecer que os profissionais técnicos (terapeutas ocupacionais, fisioterapeutas etc.) possam compartilhar a sua aplicação com profissionais da Educação Especial, de forma a realizar a avaliação de modo mais completo do que se somente um profissional de determinada área o aplicasse.

O delineamento do estudo possibilitou iniciar o processo de viabilização do instrumento PCA para a realidade nacional, em conjunto com o Roteiro PraTA desenvolvido. Os procedimentos de adaptação transcultural do PCA, construção do Roteiro PraTA e análise teórica foram executados baseados em referenciais da área da Psicometria. Especificamente sobre o processo de adaptação transcultural, se a construção de um instrumento pode ser algo bastante dispendioso, o processo de tradução e adaptação também pode se mostrar complexo quando realizado em uma realidade com um campo teórico ainda em construção sobre a temática.

Algumas dificuldades ficaram evidentes no processo de tradução do instrumento. A partir do referencial proposto por Guillemin, Bombardier e Beaton (1993) e refinado por Beaton et al. (2000), houve a necessidade de modificações de algumas das etapas devido à falta de profissionais da área que pudessem realizar a tradução do instrumento e esse processo requereu a mobilização de diversos grupos de profissionais para que a tradução fosse a mais adequada possível ao instrumento original. 
Para a adaptação do instrumento para a realidade nacional, apenas os dois itens referentes a recursos que não existiam no mercado foram excluídos, demonstrando o quanto esse instrumento ainda se mantém atualizado para os seus objetivos. Além dessas exclusões no processo de adaptação, foram inseridas duas complementaçóes ao final do instrumento, para permitir que as opiniōes da família e a disponibilidade do ambiente no qual se pretende inserir o recurso possam ser registradas.

A construção do Roteiro PraTA foi imprescindível para os objetivos de uso do instrumento PCA conforme se pretendia alcançar nesse estudo. Havia a necessidade de caracterizar tanto crianças com paralisia cerebral, enquanto alunos, como também verificar a necessidade da implementação de um recurso para o seu ambiente escolar, sem torná-lo dificultoso nem muito específico para o seu avaliador.

A definição da metodologia empregada e do grupo de juízes participantes foi essencial para garantir a qualidade teórica dos instrumentos. Nesse processo verificou-se que todos os itens formulados do Roteiro PraTA e os do instrumento PCA foram considerados pertinentes para os objetivos traçados. Além disso, os juízes puderam colaborar com diversas sugestóes, aprimorando-os. A opção por criar uma categoria de omissão de julgamento aos juízes na análise de conteúdo possibilitou que o índice de concordância sobre a pertinência dos itens não fosse influenciado por motivos indiretos que impossibilitavam os juízes de os avaliarem.

O Roteiro PraTA mostrou-se pertinente ao objetivo de contextualizar a aplicação do PCA no ambiente educacional. Os juízes indicaram ser coerente ao processo de planejamento da implementação de um recurso computacional coletar informaçóes sobre as características de identificação do aluno, do professor e da escola, e o desempenho escolar do aluno, com o intuito de indicar a necessidade de busca de um recurso de tecnologia assistiva e a disponibilidade e o interesse de todos os envolvidos para a implementação desse tipo de recurso na dinâmica de sala de aula.

Especificamente sobre o PCA, os juízes confirmaram o quão diversa pode ser a estratégia de acesso ao computador para um aluno com paralisia cerebral, indicando que o olhar dos profissionais deve estar direcionado para avaliar possibilidades de acesso via movimentos da máo, do pé, da cabeça, entre outros, e para a variedade de recursos e dispositivos que podem ser utilizados para esse fim. Além disso, confirmou-se também que a estabilidade da postura da criança é de fundamental importância e deve ser algo avaliado cautelosamente durante o processo de acesso ao computador, o que pode trazer indícios inclusive da necessidade de adaptaçôes de mobiliário no ambiente de sala de aula.

Estiveram elencadas sugestóes e críticas relacionadas a outros tipos de equipamentos e recursos, o questionamento se esses instrumentos, realmente, deverão ser dirigidos aos profissionais da educação e não somente a terapeutas, questionamentos sobre a aquisiçáo dos recursos, entre outros.

Os dados da análise de conteúdo indicaram que todos os itens dos instrumentos foram considerados pertinentes à sua proposta, com um índice de concordância entre os juízes superior a $75 \%$. Conforme o referencial utilizado (PASQUALI, 2003), um índice de concordância alto fornece subsídios para a manutenção do item no teste avaliado. Dessa forma, tanto o PCA como o Roteiro PraTA mantiveram os itens propostos inicialmente e nenhuma sugestão alcançou um índice tão elevado para a criaçáo de um novo item, mas optou-se por levar em conta todas essas propostas de mudanças e algumas modificações foram realizadas no âmbito dos manuais de instrução dos instrumentos. Em sua maior parte, essas modificaçóes disseram respeito ao direcionamento do olhar dos avaliadores para algumas variáveis no momento de aplicação dos instrumentos.

A categoria Reformulação semântica teve o maior número de falas, um total de $35 \%$. Essa categoria somada à categoria Formato do instrumento alcançou $48 \%$, subsidiando a opçáo por considerar essas contribuiçóes como a primeira fase da análise semântica dos instrumentos. Diversas sugestôes nesse sentido foram feitas, como a inserção de descriçôes mais detalhadas dos conceitos abordados no próprio contexto dos itens ou nos manuais dos instrumentos, fornecendo subsídios aos aplicadores na compreensão do que está sendo requisitado. A partir dessas contribuiçóes, poucos foram os pontos e sugestóes para a finalização da escrita dos instrumentos na segunda etapa de análise semântica dos itens.

\section{Conclusões}

Como discutido, para o processo de prescrição e adaptação de um recurso de tecnologia assistiva, a literatura aponta para a necessidade da análise de diversas variáveis influentes, provindas do 
ambiente, do contexto, do indivíduo e da tarefa. Os resultados obtidos neste estudo deixaram clara a coerência da proposta de complementação da aplicaçáo do PCA com o Roteiro PraTA quando o alvo é um aluno com paralisia cerebral, tendo em vista a necessidade de coletar dados específicos, como para caracterizar tanto a pessoa com paralisia cerebral, enquanto aluno, como também verificar a necessidade da implementação de um recurso para o seu ambiente escolar sem torná-lo dificultoso, nem muito específico para o seu avaliador.

O processo de validação transcultural de um instrumento propiciou a disponibilização de uma ferramenta para os profissionais que trabalham diretamente com alunos com paralisa cerebral, a partir de demandas de diversas áreas como a Terapia Ocupacional e a Educação Especial, acompanhando as políticas atuais.

Tem-se como intenção que no decorrer do tempo, com a utilização desses instrumentos, os profissionais possam ir internalizando o raciocínio proposto de avaliação do aluno com paralisia cerebral para o planejamento da implementação do recurso computacional no ambiente escolar e passem a pensar em todas essas informaçóes e opçóes de acesso como algo inerente de sua prática junto a esse aluno.

No entanto, também entende-se que a necessidade de se produzir conhecimentos teóricos sobre essa implementação no país deve contemplar a sistematização de procedimentos de prescrição dos recursos, o que leva a proposta deste estudo a ser pertinente ao momento atual do desenvolvimento da temática.

Por fim, sugere-se que outras populaçôes e demandas sejam investigadas, de modo a se formar um corpo teórico abrangente sobre o processo de planejamento e prescriçáo de um recurso de tecnologia assistiva na escola para o país.

\section{Referências}

ALPINO, A. M. S. Consultoria colaborativa escolar do fisioterapeuta: Acessibilidade e participaçáo do aluno com Paralisia Cerebral em questão. 2008. 190 f. Tese (Doutorado em Educação Especial)-Universidade Federal de São Carlos, São Carlos, 2008.

ALVES, A. C. J.; MATSUKURA, T. S. Reflexões sobre o uso da tecnologia assistiva no contexto escolar. Temas sobre Desenvolvimento, São Paulo, v. 18, n. 101, p. 10-16, 2011.

ANDRADI, C. S. et al. Tradução e adaptação cultural do questionário PRTEE (Patient-rated Tennis Elbow Evaluation) para a língua portuguesa. Cadernos de
Terapia Ocupacional da UFSCar, São Carlos, v. 19, n. 3, p. 281-288, 2011.

BARDIN, L. Análise de conteúdo. Tradução Luis Antero Reto. São Paulo: Ediçóes 70, 1977.

BEATON, D. E. et al. Guidelines for the process of cross-cultural adaptation of self report measures. Spine, Philadelphia, v. 25, n. 24, p. 3186-3191, 2000. http:// dx.doi.org/10.1097/00007632-200012150-00014

BERSCH, R. C. R.; PELOSI, M. B. Equipamento e material pedagógico para educação, capacitação e recreação da pessoa com deficiência física: Tecnologia assistiva: recursos de acessibilidade ao computador. Brasília: MEC: SEESP, 2007. (Portal de Ajudas Técnicas para Educação, n. 3).

BRASIL. Ministério da Educação. Politica Nacional de Educação Especial na Perspectiva da Educação Inclusiva : Documento elaborado pelo Grupo de Trabalho nomeado pela Portaria Ministerial no 555, de 5 de junho de 2007, prorrogada pela Portaria no 948 , de 09 de outubro de 2007. Brasília: MEC: SEESP, 2008. Disponível em: $<$ http://portal.mec.gov.br/seesp/arquivos/pdf/politica. pdf $>$. Acesso em 10 jan. 2009.

BRASIL. Ministério da Justiça. Comitê de Ajudas Técnicas - CORDE. Ata da III Reunião do Comitê de Ajudas Técnicas. Brasília, 2007. Disponível em: <http:// portal.mj.gov.br/corde/comite.asp >. Acesso em: 14 jul. 2009.

BRODWIN, M. G.; CARDOSO, E.; STAR, T. Computer assistive technology for people who have disabilities: computer adaptations and modifications. Journal of Rehabilitation, Washington, v. 70, n. 3, p. 28-33, jul.-set. 2004.

COOK, A. M.; HUSSEY, S. M. Assistive technologies: principals and practice. St. Louis, Missouri: Mosby, 2002.

COPLEY, J.; ZIVIANI, J. Barriers to the use of assistive technology for children with multiple disabilities. Occupational Therapy International, Malden, v. 11, n. 4, p. 229-243, 2004. http://dx.doi.org/10.1002/oti.213

DALTON, E. M. Assistive technology in education: a review of policies, standards, and curriculum integration from 1997 through 2000 involving assistive technology and the Individuals with Disabilities Education Act. Issues in Teaching and Learning, Providence, v. 1, n. 1, 2002.

DELIBERATO, D. Sistemas suplementares e alternativos de comunicação nas habilidades expressivas de um aluno com paralisia cerebral. Revista Brasileira de Educação Especial, Marília, v. 17, n. 2, p. 225-244, 2011.

DUHANEY, D. C.; DUHANEY, L. M. G. Assistive technology: meeting the needs of learners with disabilities. International Journal of Instructional Media, Tolland, v. 27, n. 4, p. 393-401, 2000.

EDYBURN, D. L. Models, theories, and frameworks: contributions to understanding special education 
technology. Special Education Technology Practice, Whitefish Bay, v. 4, n. 2, p. 16-24, 2002.

FAGUNDES, A. J. F. M. Descrição, definição e registro do comportamento. São Paulo: Edicon, 1985.

FRASER, B. A. Physicalcharacteristics assessment-computer access for individuals with cerebral palsy. 1994. 226 f. Tese. (Doutorado em Filosofia)-Temple University, Philadelphia, PA, 1994.

FRASER, B. A; BRYEN, D.; MORANO, C. K. Development of a Physical Characteristics Assessment (PCA): a checklist for determining appropriate computer access for individuals with cerebral palsy. Assistive Technology, Philadelphia, v. 7, n. 1, p. 26-35, 1995.

FUHRER, M. J. et al. A framework for the conceptual modelling of assistive technology device outcomes. Disability and Rehabilitation, London, v. 25, n. 2, p. 1243-1251. 2003. PMid:14617441. http://dx.doi.org/1 $0.1080 / 09638280310001596207$

GALVÃO, C. R. C.; BARROSO, B. I. L.; GRUTT, D. C. A tecnologia assistiva e os cuidados específicos na concessão de cadeiras de rodas no Estado do Rio Grande do Norte. Cadernos de Terapia Ocupacional da UFSCar, São Carlos, v. 21, n. 1, p. 11-18, 2013.

GUILLEMIN, F.; BOMBARDIER, C.; BEATON, D. Cross-cultural adaptation of health-related quality of life measures: literature review and proposed guidelines. Journal of Clinical Epidemiology, Maastricht, v. 46, n. 12, p. 1417-1432, 1993. http://dx.doi. org/10.1016/0895-4356(93)90142-N

LAHM, E. A.; SIZEMORE, L. Factors that influence assistive technology decision-making. Journal of Special Education Technology, Arlington, v. 17, n. 1, p. 15-25, 2002.

LENKER, J. A.; PAQUET, V. L. A new conceptual model for assistive technology outcomes research and practice. Assistive Technology, Philadelphia, v. 16, n. 1, p. 1-10, 2004. PMid:15357144. http://dx.doi.org/10.10 80/10400435.2004.10132069

LIMA, F. C.; MARINO, A. E. E.; PALHARES, M. S. Iniciação ao uso do computador: um relato de experiência com crianças com paralisia cerebral. Cadernos de Terapia Ocupacional da UFSCar, São Carlos, v. 14, n. 1, p. 33-42, 2006.

MANCINI, M. C. Inventário de avaliação pediátrica de incapacidade (PEDI): Manual da versão brasileira adaptada. Belo Horizonte: UFMG, 2005.

MARINS, S. C. F.; EMMEL, M. L. G. Formação do terapeuta ocupacional: acessibilidade e tecnologias. Cadernos de Terapia Ocupacional da UFSCar, São Carlos, v. 19, n. 1, p. 37-52, 2011.

MCGREGOR, G. et al. PCA Checklist - Physical Characteristics Assessment: computer access for individuals with cerebral palsy. Wauconda, Il: Don Johnston Incorporated, 1994.
MENDES, E. G.; LOURENÇO, G. F. Recursos computadorizados de tecnologia assistiva para estudantes com paralisia cerebral em múltiplos contextos. In: MENDES, E. G.; ALMEIDA, M. A. (Orgs.). Dimensóes pedagógicas nas práticas de inclusão escolar. 1. ed. Marília: ABPEE, 2012. p. 421-444. v. 2.

MENEGASSO, L. R. Análise teórica de itens referentes a pessoas com deficiência da Infant/Toddler Enviroment Rating Scale - Revised Edition. 2005. 162 f. Dissertação (Mestrado em Educação Especial)-Universidade Federal de São Carlos, São Carlos, 2005.

MORRISON, K. Implementation of assistive computer technology: a model for school systems. International Journal of Special Education, Reston, v. 22, n. 1. p. 83-100, 2007.

NOVELLI, M. M. P. C. Adaptação transcultural da escala de avaliação de qualidade de vida na doença de Alzheimer. 2003. 130 f. Dissertação (Mestrado em Ciências)-Universidade de São Paulo, São Paulo, 2003.

OKOLO, C. M.; BOUCK, E. C. Research about assistive technology: 2000-2006. What have we learned? Journal of Special Education Technology, Arlington, v. 22, n. 3, p. 19-34, 2007.

PASQUALI, L. Psicometria: Teoria dos testes na psicologia e na educação. Petrópolis: Vozes, 2003.

PASQUALI, L. Psicometria: Teoria e aplicação. Brasília: Editora da UNB, 1997.

PELOSI, M. B.; NUNES, L. R. O. P. A ação conjunta dos profissionais da saúde e da educação na escola inclusiva. Revista de Terapia Ocupacional da Universidade de São Paulo, São Paulo, v. 22, n. 1, p. 52-59, jan./abr. 2011.

PELOSI, M. B.; NUNES, L. R. O. P. A inclusão dos alunos com deficiência nas escolas regulares. Temas sobre Desenvolvimento, São Paulo, v. 17, n. 99, p. 99-103, 2010.

PHILLIPS, B.; ZHAO, H. Predictors of assistive technology abandonment. Assistive Technology, Philadelphia, v. 5, n. 1, p. 36-45, 1993. PMID: 10171664. http://dx.doi.org/10.1080/10400435.1993.10132205

ROCHA, A. N. D. C.; DELIBERATO, D. Tecnologia assistiva para a criança com paralisia cerebral na escola: identificação das necessidades. Revista Brasileira de Educação Especial, Marília, v. 18, n. 1, p. 71-92, 2012.

SAMESHIMA, F. S. et al. Atuação interdisciplinar na implementação de recursos para acessibilidade digital de alunos com deficiência física. In: CONGRESSO BRASILEIRO DE COMUNICAÇÃO ALTERNATIVA, 5., 2013, Gramado. Anais..., 2013. Gramado: ISAAC Brasil - International Society for Augmentative and Alternative Communication. v. 1.

SAMPAIO, M. J. T.; REIS, N. M. M. Utilização de informática na paralisia cerebral: possibilidades e recursos na clínica da terapia ocupacional. In: LIMA, C. L. F. A; FONSECA, L. F. Paralisia cerebral: Neurologia, ortopedia, reabilitação. Rio de Janeiro: Guanabara Koogan. 2004. p. 289-291. 
SANT'ANNA, M. M. M.; BLASCOVI-ASSIS, S. M.; MAGALHÂES, L. C. Adaptação transcultural dos protocolos de avaliação do Modelo Lúdico. Revista de Terapia Ocupacional da Universidade de São Paulo, São Paulo, v. 19, n. 1, p. 34-47, jan./abr. 2008.

SILVA, D. B. R.; MARTINEZ, C. M. S.; SANTOS,

J. L. F. Participação de crianças com paralisia cerebral nos ambientes da escola. Revista Brasileira de Educação Especial, Marília, v. 18, n. 1, p. 33-52, 2012.

VERZA, R. et al. An interdisciplinary approach to evaluating the need for assistive technology reduces equipment abandonment. Journal of Multiple Sclerosis, New York, v. 12, n. 1, p. 88-93, 2006. http://dx.doi. org/10.1191/1352458506ms1233oa

\section{Contribuição dos Autores}

Gerusa F. Lourenço: responsável pela condução do estudo e redação do texto. Enicéia G. Mendes: responsável pela orientação do estudo e revisão do texto.

\section{Fonte de Financiamento}

PROESP/CAPES 